\title{
Modelling the redistribution of trace elements for upper mantle pressures
}

\section{JULIA MARLEEN SCHMIDT AND LENA NOACK}

Freie Universität Berlin

Presenting Author: julia.schmidt@fu-berlin.de

Melt-induced elemental redistribution processes inside the Earth influence the composition of magmas and residual mantle heavily. During mantle melting, trace elements redistribute between solid mantle material and partial melt. Partition coefficients describe an element's ability to be either incorporated into the solid or redistributed into the newly formed melt. Due to a lower density compared to surrounding solid rock, partial melt that was generated in the upper mantle will rise towards the surface, leaving the upper mantle depleted in incompatible trace elements and the crust enriched. To be able to trace this redistribution behavior in mantle evolution models, it is important to consider that partition coefficients are sensitive towards temperature, pressure, and composition. However, due to lacking high pressure models and experimental data, mantle evolution models typically rely on constant partition coefficients.

In this study, we developed a thermodynamic model for sodium in clinopyroxene after Blundy et al. (1995) [1] and we show that partition coefficients vary by several orders of magnitude between the surface and the mantle transition zone. Based on the thermodynamic model results, we deduced a P-T dependent equation for sodium partitioning that is applicable up to $12 \mathrm{GPa}$ between the peridotite solidus and liquidus. Sodium is an almost strain-free element in jadeite and therefore can be used as a reference to model partition coefficients for other elements, including heat producing elements like $\mathrm{K}$, Th, and U. As a reference for other trace elements, we now have the opportunity to insert P-T dependent partition coefficient calculations of any trace element into mantle melting models. This will help elemental redistribution calculations to be more accurate and can be also used, if heat producing elements are taken into account, to investigate the evolution of the mantle and crust.

[1] Blundy, J. et al. (1995): Sodium partitioning between clinopyroxene and silicate melts, J. Geophys. Res. 100, 1550115515.

[2] Schmidt, J.M. and Noack, L. (2021): Parameterizing a model of clinopyroxene/melt partition coefficients for sodium to higher upper mantle pressures (to be submitted) 